\title{
Evaluating CPI and SPI Indicators in Project Management Maturity Evolution
}

\author{
Luciana de Q. Leal Gomes ${ }^{1}$, Reinaldo C. M. Gomes ${ }^{2}$, Cristine M. Gomes de \\ Gusmão $^{3}$, Hermano Perrelli de Moura ${ }^{1}$ \\ ${ }^{1}$ Centro de Informática (CIn) -Universidade Federal de Pernambuco (UFPE) -Brasil. \\ ${ }^{2}$ Departamento de Sistemas de Computação (DSC) - Universidade Federal de Campina \\ Grande - Brasil. \\ ${ }^{3}$ Programa de Pós-graduação em Engenharia Biomédica - Centro de Tecnologia e \\ Geociências (CTG) - Universidade Federal de Pernambuco - PE, Brasil \\ \{lql, hermano\}@cin.ufpe.br, reinaldoddsc.ufcg.edu.br, \\ cristine.gusmao@pq.cnpq.br
}

\begin{abstract}
Project management has become a common subject in Software Engineering and an everyday task in software organizations. In this task, the effective use of technologies can determine the success of any business; affect quality and ability to provide products and services on time. According to some authors, success in project execution can be associated with organization maturity. Organizations search for project management maturity in order to improve their management process and increase client satisfaction. Maturity is related to cost, time and quality, and can determine the success of projects. In the context of project management, we have two important indicators: Schedule Performance Indicator (SPI) and Cost Performance Indicator (CPI). SPI indicates whether the budgeted costs for work scheduled to date exceed the budgeted costs for the work performed to date. CPI indicates whether the actual costs for the work performed to date exceed the budgeted costs for the work performed to date. These indicators give information about whether or not the project is on track, so they are important factors which represent success in project management. This paper discusses how Cost/Schedule Performance Indicators are related to project management maturity and presents the results based on IT professionals' opinion analysis.
\end{abstract}

\section{Introduction}

The driving forces behind the use of project management today include the dynamic nature of most projects, and flexibility required to meet changes in the work environment [Ali and Money 2005]. In this scenario, high rates of failure may indicate the low level of maturity in project management.

The maturity analysis, however, can be quite complex, since it is necessary to understand and apply a specific maturity model. Maturity models do not provide a guarantee of success for any given project, only increase this probability. They allow an organization to assess its generic capability against best-known industrial practices 
[Ahiable and Dalcher 2005]. This assessment submits the organization to exhaustive analysis and classification methods, usually quite extensive questionnaires.

A way to assess maturity is use of indicators, which can provide information independently maturity models. In order to investigate this possibility, this study selected two candidate indexes. They are the CPI (Cost Performance Index) and SPI (Schedule Performance Index), present in the Earned Value technique application [Abba 2001], [PMBOK 2004]. When used and stored properly, they can generate a project database able to assess their management.

Attarzadeh and Hock (2009) use CPI, SPI, Cost Variance (CV), and Schedule Variance (SV) in order to ensure project success. The authors affirm that using these variables in prediction can help to management team before any happened find a solution, and it helps to project success. Besides CPI and SPI, other indicators are used to assess maturity in software projects [Bianchi 2001], [Ramasubbu and Balan 2009]. Also related with this subject, Lu, Shu and Li (2008) study the correlation between maturity and performance indexes and Xian and Xue-qing (2010) studies the evaluation indicators of project management maturity for project-oriented organizations, applying a neural network in order to overcome the defect of other methods.

Values not desirable in the CPI and SPI indexes represent failure in planning. Whereas, as organizations mature their management processes, projects should be finished increasingly within the boundaries of planned budget and schedule, the indexes for these areas must reflect this evolution.

Based on this, the goal of this work is identify organizations in higher or lower levels of project management maturity from CPI and SPI values more or less stable. To do this, we need to check before the behavior of these indexes over the evolutionary process. Considering the context presented, the objective of this study is to know if it is possible to use CPI and SPI indicators in order to explain or assess project management maturity. We performed this assessment through a survey, in which respondents reported their observations on projects that they participated.

The structure of the paper is as follows: Section 2 presents the Earned Value Analysis technique. Section 3 shows CPI and SPI mapping in project management maturity models characteristics. In this section we searched for the CPI and SPI employment in these models. Section 4 brings the maturity evolution pattern and the maturity levels definition used in this work. Section 5 shows the CPI and SPI assessment as project management maturity indicators (we used a questionnaire as research instrument). Finally, Section 6 gives the conclusions and future remarks.

\section{Earned Value Analysis}

PMBOK $^{\circledR}$ Guide (Project Management Body of Knowledge) emphasizes the importance of monitoring and controlling the activities of all project management areas. In order to perform this, it is necessary establish metrics and measure techniques to identify the variations that can occur.

Earned Value Analysis (EVA), which is one of these techniques, allows performance evaluation during all the project execution. Despite of being an old technique, EVA has been better accepted in the last years [Abba 2001]. 
The Earned Value was created in 1967 under the name of Cost / Schedule Control Systems Criteria (C/SCSC), the Department of Defense United States of America as a breakthrough in managing military projects. At that time, the C / SCSC was defined as mandatory for all contracts and projects of the army [Abba 2001]. Later in the 90s, the methodology emerged in the corporate environment and has evolved since then.

In the PMBOK ${ }^{\circledR}$ Guide, the EVA technique is contained and explained in the Costs Management knowledge area. However, it is possible to extract information from its application to schedule and even scope. Its application involves the following variables [PMBOK 2004]:

1. Planned Value (PV). It refers to the estimated cost in planning for an activity or WBS component structure (Work Breakdown Structure).

2. Earned Value (EV). It refers to the amount budgeted for the work actually completed to date.

3. Actual Cost (AC). It refers to the overall cost of the work to date.

4. Cost Variance (CV). It is the difference between the value (EV) and actual cost (AC).

5. Schedule Variance (SV). It is the difference between the value (EV) and the planned value (PV).

From the variables presented, we can extract performance time and cost indicators the project. Cost Performance Index (CPI) is the ratio between EV and AC. CPI values over 1 indicate projects over budget, while lower values show that the estimated costs have not been met. Schedule Performance Index (SPI) is the ratio between EV and PV. SPI values less than 1 indicate delay in the project, while higher values show that the project is running ahead of schedule.

Both indexes listed above are the basis of the study presented in this work. The CPI and SPI usage in the technique of EVA allows the identification of gaps in planning during the project, and the degree of such deviations. It happens because EVA can be applied at any time throughout the project and the indices provide a quantitative measure of this at analysis.

\section{Mapping CPI and SPI in Maturity Management Models}

In this section we look for similarities among maturity models and the indicators CPI and SPI. As we can see in the models, the importance of cost and schedule control is present. Nevertheless, the methodologies employed to perform this control can vary from one organization to another, and they are not detailed in these documents.

CMMI - Capability Maturity Model Integration [CMMI 2010] presents three direct citations to the EVA technique. The first citation is described as a process area on the maturity level 2. The measurement and analysis activities still are valid in higher levels, but the activities are developed intensely on the level 2.

On the second CMMI maturity level, metrics are project-oriented, not processoriented. They aim to reach the goals of the specific project according to the planning. In 
this case, a measurement and analysis activity compares the existing results during the project with the initial values. This description fits with the EVA application, which is mentioned as an example of derivative measures commonly used, in the practice "Specify Measurements".

The second citation occurs on the Project Control and Monitoring project management process area. Still in the level 2, the generic practice "Manage Configurations" mentions EVA reports as examples of work products.

The third citation to the EVA in CMMI occurs in Casual Analysis and Resolution, described as a support process area on the maturity level 5. In this level, there is a single process and it is institutionalized, metrics process-oriented and the analysis are looking for the continuous improvement. Fails in each project need to be reported and metrics capable to evaluate the process and its groups are necessary in order to improve.

For this purpose, one of the CMMI specific metrics is "Determinate Defect Cause" which search for the reported problems root. The first specific practice in this activity is called "Select Defect Data for Analysis". In this practice, the earned value measurements figure as examples of relevant data in found problems. The CPI is founded as example of it.

In CMMI, CPI and SPI also are mentioned in Risk Management Processes Area. In the parameter definition, boundary values are chosen to the cited indexes in order to define priorities in risks, and what the limits until we can accept them or we should demand intervention.

In a similar way, OPM3 (Organizational Project Management Maturity Model) has a best practices directory composed of two or more capabilities each one [OPM3 2003]. The presence of best practices in an organization makes possible its maturity analysis.

The capability development should produce tangible work results. This result assessment demands metrics definition, and OPM3 uses KPIs (Key Performance Indicators) to do this. OPM3 works with project, programme and portfolio domains, and the KPIs should be considered by each domain.

The model follows an approach to manage programme and portfolio domains similar to the project one. The model uses the same set of process groups: Initiation, Planning, Execution, Monitoring and Control, and Enclosure. To each group, there are processes defined, capabilities mapped to the domain processes and interdependencies defined.

The greater number of the citations occurs like this, with one exception, where the EVA appears as a part of control attribute, in the program scope verification, in control group. All the remainder mentions that the EVA technique happens in the following process groups:

1. Planning: Programme and Portfolio Development Planning Process.

2. Control: Programme and Portfolio Cost Control Process, Programme Performance Report Process, Portfolio Scope Verification Process. 
Kerzner (2001) refers to EVA technique when talks about continuous improvement at maturity level 5. When the author makes an evolutive comparison among organizational structure in organizations, he shows the strong trend to be horizontal ones. Historically, costs were calculated in a vertical way, which produces problems because the managers did not have enough knowledge and vision to make these estimations. In project execution, some budget deviation in project execution occurred. Now, project management methodologies require this plan be horizontal and use EVA.

The approach adopted by P3M3 - Portfolio, Programme and Project Management Maturity Model [P3M3 2008], which divides the model in seven perspectives that are treated in an evolutive way in each maturity level, treats financial management (cost management) in all five levels. However, the EVA appears explicitly as a specific attribute of the perspective on the level 4 .

At last, Prado-PMMM (Project Management Maturity Model) [Prado 2008] does not make explicit references about EVA technique. Nevertheless, the model adopts the knowledge areas division established by $\mathrm{PMBOK}^{\circledR}$ Guide, and the area cost management present in the guide contains the EVA technique.

When analyzing each level aspect presented by Prado-PMMM, the application of EVA fits well on the descriptions of maturity level 4. In this level, we can see as main characteristic the identification of causes of goals deviation.

The earned value management can emerge from level 3, which has well established project management as characteristic. On the level 4, the manager can use the EVA in order to identify fails points in planning.

\subsection{Use of CPI and SPI}

According to the mapping presented in the previous Section, we can resume the indicators CPI and SPI main utilities. First, in project management maturity strategic planning, some metrics will be defined in order to evaluate success. In this occasion, CPI and SPI can demonstrate the project progress according to budget and schedule, and also scope.

With the metrics defined, it is necessary incorporate them to the processes. The indicators will be useful to demonstrate the final situation of the project and to identify deviations during the project in control activities.

EVA can be used beyond the budget and schedule areas. Risk management can extract benefits of this technique, when using CPI and SPI boundary values in contingency plans application [Hillson 2004].

Once the process is established as a standard, the indicators will be useful in project success measurement, and also in effectiveness process evaluation, identifying gaps to be addressed and aspects to be improved.

When observing the CPI and SPI mapping and its analysis, we can note the technique application and the values of cost and time change as the maturity level increases. Therefore, not only the CPI and SPI values can be valid in maturity assessment, but also their application and the point of the process they appear. 
CPI and SPI applied in disorderly, only in success project measurement, and without representative results to the future, are low maturity level evidence. These indicators standard application to every project, during its execution, characterize an intermediate level management. In addition, these indicators usage in processes analysis may indicate an organization which project management reach higher maturity levels. Consequently, the study of CPI and SPI indicators in organizations can lead to the maturity analysis through two aspects:

1. Values in projects coherent with planning: Reduced variation in organizations with high maturity levels.

2. EVA application: Metrics oriented to processes in organizations with high maturity levels.

\section{CPI and SPI as Maturity Indicators}

The maturity models presented in this work have distinctions in aspects of each level, except the OPM3, which does not have a level separation. However, all of them treat project management in an evolutive way. Despite of the models establish different boundaries, and each one develop its own method to organize and present the activities, the development order is similar in all of them.

In proposed generic level definition, the maturity levels start from a point with no strategic planning is established. During the evolution, the work methodology, coworkers and stakeholders' vision will change.

The intention is to pass the criteria from a qualitative view to a quantitative view. It means the concern is no longer finishing projects, but finish them respecting values, specifications and constraints well defined.

Considering the concept incorporation during the time, we expect the organization step by three phases. On the first phase there is no planning at all, neither process to be followed. On the second phase processes are integrated to the routine and the concern with each activity execution is constant. At last, processes become intuitive, eliminate the hassle of constant verification, and make the benefits become more visible. In other words, the level definition presented in this work follows the principles:

1. Evolution from qualitative analysis to quantitative analysis.

2. Evolution from controlled processes to intuitive processes.

\section{CPI and SPI Assessment}

In order to search for evidence in practice about the theories presented here, an online questionnaire was developed and distributed to IT professionals. The research was available online at SurveyMonkey [SurveyMonkey 2009]. The questionnaire has ten questions according to the following structure:

1. Respondent profile. Type of organization (public, private, nonprofit, or work by his/herself), organization employees mean, experience, and certifications possession. 
2. Organization maturity. This section has a goal to know about maturity aspects in organization. Maturity model usage, maturity project management aspects, and how improves project management considering the organization weaknesses.

3. Cost and schedule management. EVA usage, On-time and on-budget projects frequency, over budget and over time frequency, and project abortion caused by over budget or over time frequency.

\subsection{Results Analysis}

The proposed questionnaire was sent to mailing lists of the PMI-PE (Project Management Institute - Pernambuco) chapter, in Brazil, and three Brazilian organizations (Serviço Federal de Processamento de Dados em Pernambuco SERPRO/PE, Ministério Público da Paraíba - MP/PB, Centro de Estudos Avançados do Recife - CESAR/PE). This questionnaire had 37 respondents. The greater number of them represents private $(54.1 \%)$ and large organizations, with more than 100 employees (59.5\%). The respondents experience in the Information Technology area is about five years or more $(58.5 \%)$.

Only $37.8 \%$ have some certification, and the majority of them focus on software development, not project management. 11\% have PMP (Project Management Professional) certification. However, the benchmarking research promoted by PMI Project Management Institute [PMI 2008] shows the great part of organizations does not consider certifications as an exigency.

The low adherence of Brazilian companies to specific maturity models is also clear in the answers. $72.2 \%$ of the respondents work in organizations which does not adopt maturity models. However, among the maturity models adepts, CMMI was the most cited model.

In order to measure maturity models levels of the respondents, the questionnaire raise essential aspects, like single methodology and metric usage. Before to show the classification achieved, some points should be explained:

1. The presented division is not a real classification. It is a representation. A real classification requires a thorough analysis from the perspective of the adopted model. In order to divide organizations and to make possible the results analysis, we chose the stronger characteristics of each level which we found through the intersection of several models.

2. The survey respondents are not always faithful to reality by exposing their organizations' situation, even in anonymous surveys, as is the case.

We can observe that organizations are in levels 1 and 3 , and none of the organizations reach the maximum level. According to the Figure 1, the EVA employment shows that most project managers do not use or even know the technique.

From the collected data, we analyzed level to level, and tried to explain the evolutionary behavior of maturity in project management for the purposes proposed. The percentages does not need to add up exactly $100 \%$, since, depending on the question, respondents may refrain from responding, or even select more than one option. 
13 respondents (35.1\%) classified their organizations as level 1. Just $7.6 \%$ affirmed use EVA, but in few projects. $38.4 \%$ does not know this technique. Some aspects observed among the responses of the first level representatives, for the initiatives to be taken in their respective organizations are presented below.

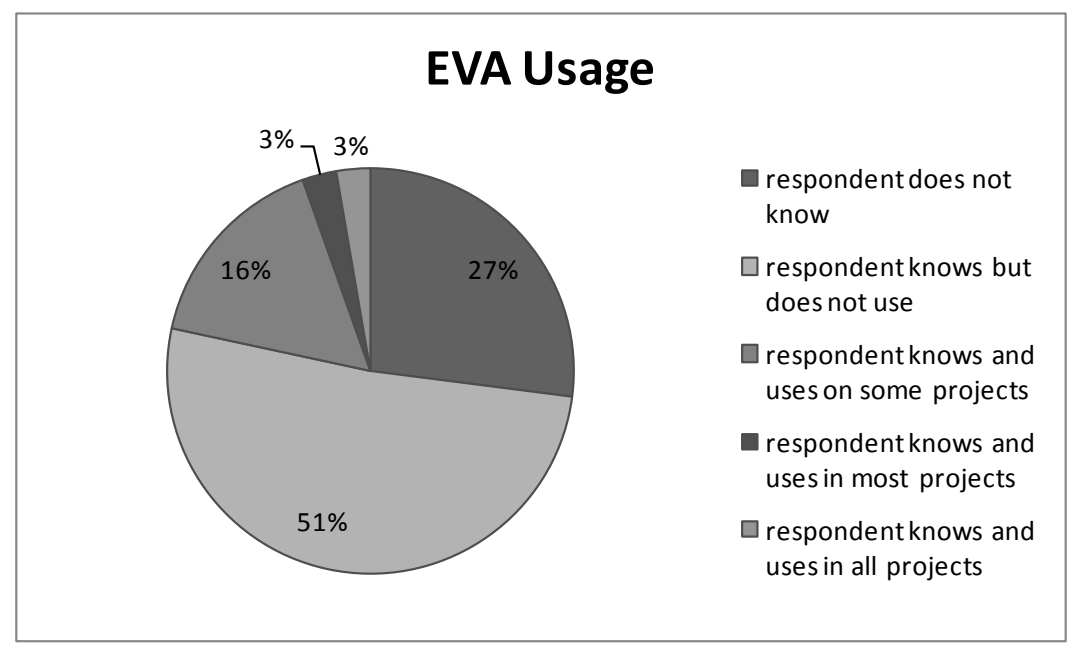

Figure 1. Respondents who know and/or use EVA

In level 2, we classified $18.9 \%$ of respondents ( 7 respondents). Of these, $28.5 \%$ reported using EVA, but only in some projects. The majority, 57.1\% claimed does not know the technique.

$37.8 \%$ of respondents were classified as maturity level 3 (14 respondents). Of these, only $28.5 \%$ said they use EVA, $50 \%$ of them use it only in a few projects, $25 \%$ in most projects and 25\% say they use Earned Value for all projects. Only $7.1 \%$ of the 14 respondents claimed not to know the technique.

We classified $8.1 \%$ of respondents as maturity level 4 (3 respondents). Of these, everyone knows EVA, however, only $33.3 \%$ use and then only in some projects.

Table 1. Maturity initiatives considered more important

\begin{tabular}{|c|c|c|c|c|}
\hline $\begin{array}{c}\text { Maturity Initiatives } \\
\end{array}$ & Level 1 & Level 2 & Level 3 & Level 4 \\
\hline Project management processes improvement & $23 \%$ & $42.8 \%$ & $42.8 \%$ & $33.3 \%$ \\
\hline Training in project management & $38.4 \%$ & $28.5 \%$ & $14.2 \%$ & $33.3 \%$ \\
\hline $\begin{array}{l}\text { Developing a single project management } \\
\text { methodology }\end{array}$ & $15.3 \%$ & $28.5 \%$ & - & - \\
\hline $\begin{array}{l}\text { Project performance } \\
\text { implementation and usage }\end{array}$ & - & $14.2 \%$ & $21.4 \%$ & - \\
\hline $\begin{array}{l}\text { Programme or portfolio management } \\
\text { Processes implementation }\end{array}$ & - & - & - & $33.3 \%$ \\
\hline Benchmarking & $21.4 \%$ & - & $21.4 \%$ & - \\
\hline
\end{tabular}

In the questionnaire we asked about initiatives which can bring more benefits to the organization in question. We used a scale from 1 to 6 , where 1 means the less important initiative and 6 means the more important one. The project management maturity initiatives are in the Table 1 (above), as well as, the more important ones according to each level. 
At level 1, the respondents are more concerned about project management training. It occurs because the organization is developing its knowledge in project management. The documented process employment is difficult to these organizations, but the respondents are concerned about it. Benchmarking, performance indicators usage and programme/portfolio management are not a preoccupation yet.

Respondents at level 2 are less concerned with training than those in level 1. But the percentage is still relevant. There is a higher concern about single methodology and performance indicators than level 1 .

In the responses we found an interesting observation regarding the results fitted in level 3: the use of single methodology was not considered important by respondents. We remember that single methodology is a stronger characteristic of organizations at level 3.

The same initiatives were evaluated as less important for some respondents. According to each level, the initiatives chose as less important were the following:

Table 2. Maturity initiatives considered less important

\begin{tabular}{|c|c|c|c|c|}
\hline Maturity Initiatives & Level 1 & Level 2 & Level 3 & Level 4 \\
\hline Project management processes improvement & $7.6 \%$ & $14.2 \%$ & - & - \\
\hline Training in project management & $7.6 \%$ & - & $7.1 \%$ & - \\
\hline $\begin{array}{l}\text { Developing a single project management } \\
\text { methodology }\end{array}$ & - & $14.2 \%$ & $14.2 \%$ & - \\
\hline $\begin{array}{l}\text { Project performance } \\
\text { implementation and usage }\end{array}$ & $7.6 \%$ & - & - & - \\
\hline $\begin{array}{l}\text { Programme or portfolio management } \\
\text { processes implementation }\end{array}$ & $23 \%$ & - & $28.5 \%$ & - \\
\hline Benchmarking & $38.4 \%$ & $57.1 \%$ & $28.5 \%$ & - \\
\hline
\end{tabular}

As we can see in Table 2, the percentages of maturity initiatives are in accordance with each level characteristic. In level 4, there were no items marked with low importance, which shows all respondents at this level were concise selection of initiatives. Again, it is interesting to note the consistency of the factors considered relevant among the representatives of level 4, where focus is the search for evidence that could lead to process improvement.

Table 3. Frequency of problems with budget estimation by level

\begin{tabular}{|l|c|c|c|c|}
\hline \multicolumn{1}{|c|}{ Problems with budget estimation } & Level 1 & Level 2 & Level 3 & Level 4 \\
\hline $\begin{array}{l}\text { The project is developed and completed within } \\
\text { the original cost estimation }\end{array}$ & $7.6 \%$ & $14.2 \%$ & $7.1 \%$ & $33.3 \%$ \\
\hline $\begin{array}{l}\text { The project is completed at a cost lower than } \\
\text { estimated in the initial }\end{array}$ & - & - & $7.1 \%$ & - \\
\hline $\begin{array}{l}\text { Cost variances are identified and corrected } \\
\text { during the project }\end{array}$ & $15.3 \%$ & $28.5 \%$ & $42.8 \%$ & $33.3 \%$ \\
\hline $\begin{array}{l}\text { Cost variances are identified during the } \\
\text { project, but are not corrected and the project } \\
\text { exceeds the budget }\end{array}$ & $46.1 \%$ & $14.2 \%$ & $50 \%$ & $33.3 \%$ \\
\hline $\begin{array}{l}\text { Cost variances are not identified during the } \\
\text { development of the project and the project is } \\
\text { completed above the planned budget }\end{array}$ & $46.1 \%$ & $28.5 \%$ & $35.7 \%$ & $33.3 \%$ \\
\hline The project is not completed by cost overruns & $30.7 \%$ & $28.5 \%$ & $35.7 \%$ & $33.3 \%$ \\
\hline
\end{tabular}


We also analyzed the budget and schedule problems in organizations. According to the budget, the frequency which the following would occur in the organization's projects is presented in Table 3 .

According to schedule, the frequency with which the following would occur in the organization's projects:

Table 4. Frequency of problems with schedule estimation by level

\begin{tabular}{|l|c|c|c|c|}
\hline \multicolumn{1}{|c|}{ Problems with schedule estimation } & Level 1 & Level 2 & Level 3 & Level 4 \\
\hline $\begin{array}{l}\text { The project is developed and completed within } \\
\text { the original schedule estimation }\end{array}$ & $7.6 \%$ & $14.2 \%$ & - & $33.3 \%$ \\
\hline $\begin{array}{l}\text { The project is completed before the time } \\
\text { estimated in the initial }\end{array}$ & - & $14.2 \%$ & - & - \\
\hline $\begin{array}{l}\text { Schedule deviations are identified and } \\
\text { corrected during the project }\end{array}$ & $23 \%$ & $42.8 \%$ & $42.8 \%$ & $33.3 \%$ \\
\hline $\begin{array}{l}\text { Schedule deviations are identified during the } \\
\text { project, but are not corrected and the project } \\
\text { exceeds the budget }\end{array}$ & $53.8 \%$ & $42.8 \%$ & $28.5 \%$ & - \\
\hline $\begin{array}{l}\text { Schedule deviations are not identified during } \\
\text { the development of the project and the project } \\
\text { is completed above the planned budget }\end{array}$ & $53.8 \%$ & $14.2 \%$ & $42.8 \%$ & $33.3 \%$ \\
\hline $\begin{array}{l}\text { The project is not completed on schedule } \\
\text { overrun }\end{array}$ & $38 \%$ & $14.2 \%$ & $42.8 \%$ & $33.3 \%$ \\
\hline
\end{tabular}

In the Figure 2, we present the trend to complete more projects on time and on budget as the maturity increases. This is due to the processes improvement and better factors control of the project during its implementation. On the graphic, we also can note that more projects were completed within budget and schedule set forth as the maturity increases. This is due to improved processes and better project factors control during its implementation.

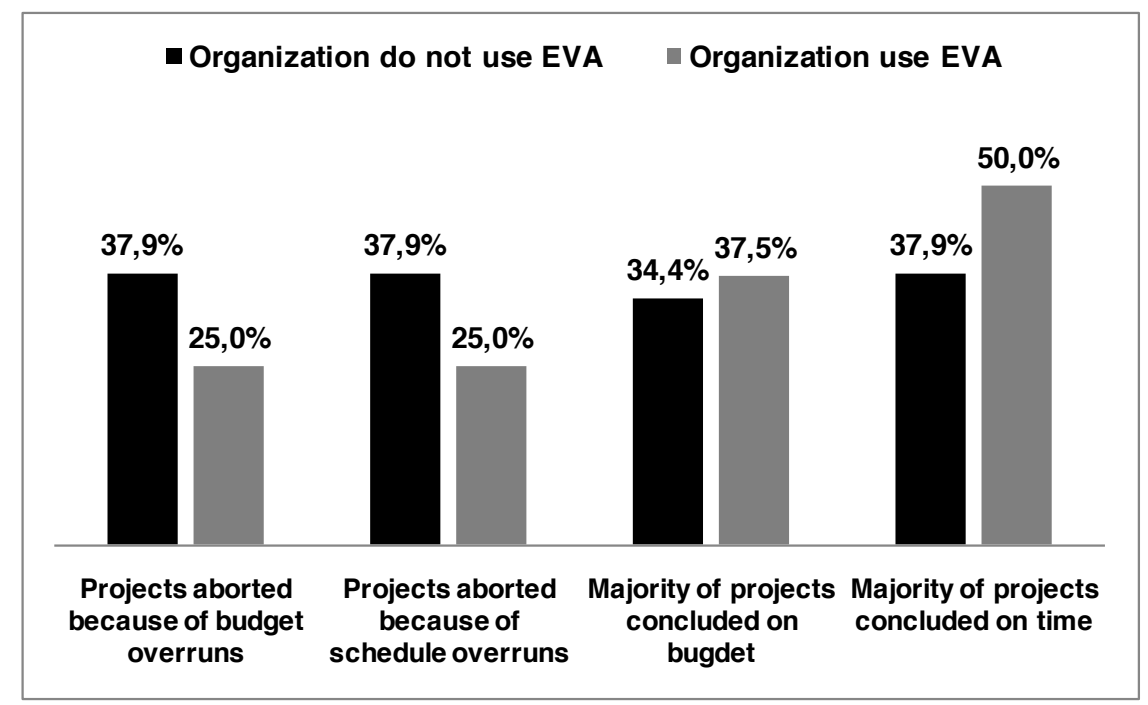

Figure 2. Impact of EVA employment in projects

When analyzing the information here explained from values taken from the questionnaire, we can reach the following conclusions:

1. The EVA usage increased as maturity evolved. 
2. The budget and schedule control became more efficient with the maturity development.

According to these two conclusions, the EVA usage, and improvements in cost and time aligned with the evolving maturity, it is possible to deduce the behavior of CPI and SPI indicators along this trend. Another important aspect when considering the indicators increasing usage, in alignment with the projects improvement on time and cost, is the gaps identification increase still in the development of the project. It enables the adoption of contingency measures and which can be seen in the analysis.

It is possible to note improvements in the figures for respondents who use EVA, compared to those who do not. Again, the verification shows benefits in the EVA implementation to control cost and schedule. The CPI and SPI calculation presented more consistent values for these projects than for others, which do not use the technique. Similarly, the values were more consistent at maturity higher levels than at lower levels.

Therefore, it is possible to trace the maturity evolution in project management in an organization based on these indicators. They indicate lack of planning that must be mitigated as the management evolves. When interpreting the values of the indicators, they can both fail to express the more for less, costs (CPI) and schedule (SPI).

\section{Conclusions and Future Remarks}

This study aimed to verify the possibility of using well known project management indicators for maturity assessment. CPI and SPI are the indicators proposed. In order to allow maturity assessment independent of specific models, we presented generic levels classification for maturity according to the strengths of development standards.

Despite of the relatively small sample, it was possible to verify the costs and schedule management improvement among organizations with higher levels of maturity and adept to EVA. The technique appears most often as the management evolves, and along these steps we can check: (1) Decrease of unfinished projects over budget or schedule; (2) Reduction of budget and schedule not identified deviations during the project; and (3) Increase in projects completed in accordance with the planned budget and schedule.

All these aspects are reflected in the indicators to be measured during the project, at its conclusion, and finally archived. Thus, using a sample rate of several projects, we can check their application, how they are used, and which values take in order to assess the current project management level of the organization, and identify areas which can be improved.

The possibility of using the CPI and SPI indicators in order to assess maturity in project management was our contribution in this work. Nevertheless, it is necessary to perform others evaluations in order to use them in maturity assessment properly.

As future remarks, we suggest to search real data in organizations to establish the use of indicators, such as CPI and SPI. Moreover we also suggest conducting a study to establish values that the indicators take on each general level of maturity, and conduct similar studies based on other metrics used in projects. 


\section{References}

Abba, W. F. (2001) "How Earned Value Got to Prime Time: A Short Look Back and Glance Ahead", The Measurable News, Spring. PMI College of Performance Management.

Ahiable, A.; Dalcher, D. (2005) "Failure, Success, and Maturity in Projects", IEEE International Engineering Management Conference.

Ali, A.; Money, W. (2005) "A Study of Project Management System Acceptance", Hawaii International Conference on System Sciences.

Attarzadeh, I.; Hock, O. (2009) "Modern Project Management: A New Forecasting Model to Ensure Project Success", International Conference on Future Computer and Communication.

Hillson, D. (2004) "Earned Value Management and Risk Management: A Practical Synergy", Available at: http://www.risk-doctor.com/pdf-files/cev-b1004.pdf.

Bianchi, A. J. (2001) "Management Indicators Model to Evaluate Performance of IT Organizations", Portland International Conference on Management of Engineering and Technology.

Kerzner, H. (2001) "Strategic Planning for Project Management using a Project Management Maturity Model”, $1^{\text {a }}$ ed. John Wiley \& Sons.

Lu, X.; Shu, L.; Li, J. (2008) "Correlation Analysis between Maturity Factors and Performance Indexes in Software Project", International Conference on Industrial Engineering and Engineering Management.

P3M3 (2008) "Portfolio, Programme \& Project Management Maturity Model", P3M3 Public Consultation Draft 2.0.

OPM3 (2003) "Organizational Project Management Maturity Model”, Knowledge Foundation, Pennsylvania: Project Management Institute.

PMBOK (2004) "PMBOK ${ }^{\circledR}$ Guide: Um guia do conjunto de conhecimentos do gerenciamento de projetos", Pennsylvania: Project Management Institute, 3. ed.

PMI (2008). "Benchmarking em GP no Brasil - Relatório 2008 (Visão Geral)", Available at: http://pmi-rio.ning.com/page/benchmarking-1.

Prado, D. (2008) "Maturidade em Gerenciamento de Projeto", Série Gerência de Projetos. Vol. 7, INDG Tecs.

Ramasubbu, N.; Balan, R. K. (2009) "The Impact of Process Choice in High Maturity Environments: An Empirical Analysis", IEEE International Conference on Software Engineering.

CMMI (2010) "Capability Maturity Model Integration for Development", Version 1.3. CMU/SEI-2010-TR-033. USA.

SurveyMonkey(2009) Available at: http://www.surveymonkey.com/

Xian, Z.; Xue-qing, W. (2010) "Fuzzy Evaluation of Project Management Maturity Model Based on Neural Network", IEEE International Conference on Advanced Management Science. 